\title{
Knowledge and perception toward colorectal cancer screening in east of Iran
}

\author{
Farzad Bidouei, Saeid Abdolhosseini, Narges Jafarzadeh, Azra Izanloo, Kamran Ghaffarzadehgan*, Ali Abdolhosseini, \\ Fahimeh Khoshroo, Mitra Vaziri, Toktam Tourdeh, Hami Ashraf
}

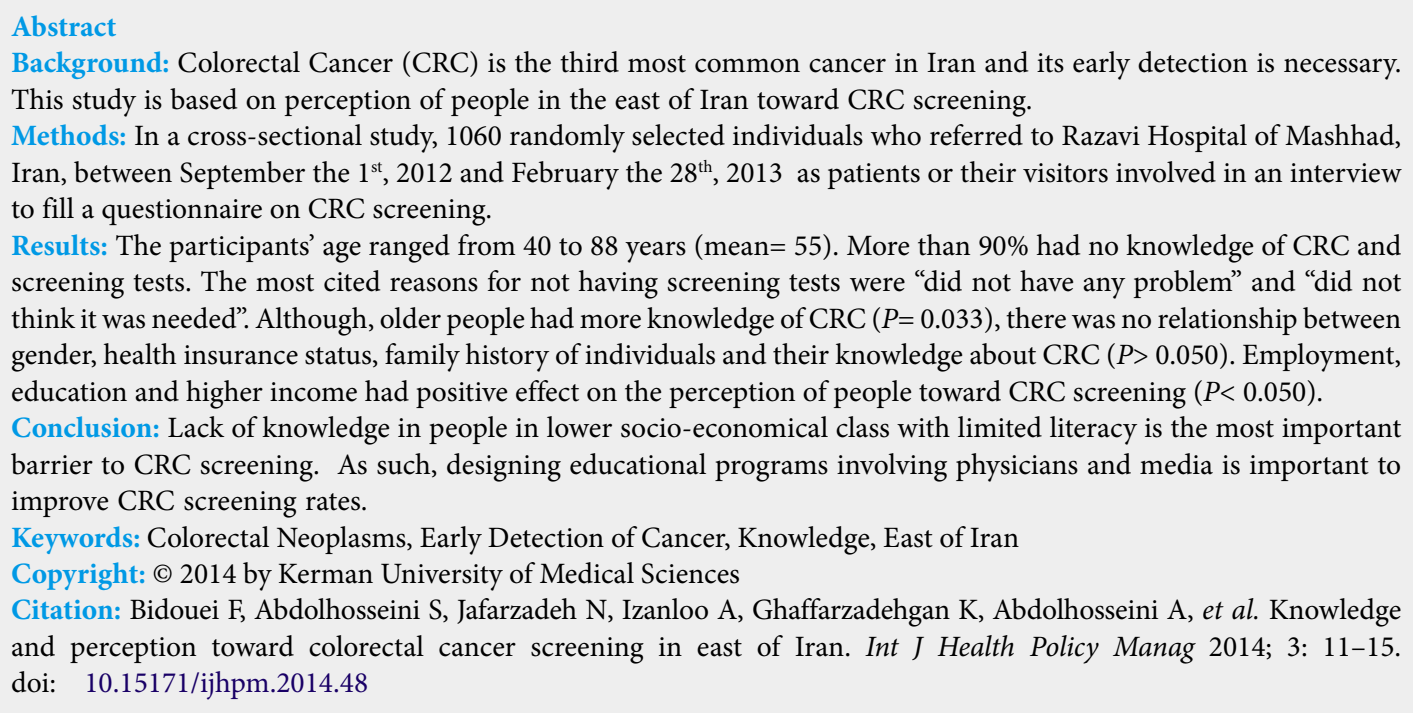
screening tests. The most cited reasons for not having screening tests were "did not have any problem" and "did not think it was needed". Although, older people had more knowledge of CRC $(P=0.033)$, there was no relationship between gender, health insurance status, family history of individuals and their knowledge about CRC $(P>0.050)$. Employment, education and higher income had positive effect on the perception of people toward CRC screening $(P<0.050)$.

Conclusion: Lack of knowledge in people in lower socio-economical class with limited literacy is the most important barrier to CRC screening. As such, designing educational programs involving physicians and media is important to improve CRC screening rates.

Keywords: Colorectal Neoplasms, Early Detection of Cancer, Knowledge, East of Iran

Copyright: $\odot 2014$ by Kerman University of Medical Sciences

Citation: Bidouei F, Abdolhosseini S, Jafarzadeh N, Izanloo A, Ghaffarzadehgan K, Abdolhosseini A, et al. Knowledge and perception toward colorectal cancer screening in east of Iran. Int J Health Policy Manag 2014; 3: 11-15. doi: $10.15171 /$ ijhpm.2014.48

Article History:

Received: 7 March 2014 Accepted: 10 May 2014 ePublished: 18 May 2014

\section{Introduction}

The prevalence of Colorectal Cancer (CRC) in Asia is high and the number of new cases is rapidly increasing in both genders (1-3). In Iran, CRC is the third most common cancer in women and fifth in men and is known as the fifth cause of cancer death (4). CRC is mostly prevalent in older people but in Iran there has been a great rise in its incidence among young individuals in recent decades, especially in those with positive history of CRC in the first or second degree relatives (4).

The incidence of this malignancy is reducing in many western countries, largely due to improvements in treatment and increased people's awareness and early detection. On the other hand, the rates continue to increase in communities with less social knowledge and more limited health resources (1).

The majority of CRC incidences and deaths can be prevented by applying public awareness about cancer prevention and by raising the use of available screening tests.

By screening we are able to find and remove adenomatous polyps which are in premalignant state of CRC $(5,6)$. Also being screened regularly and at the recommended intervals increases the probability of cure with less extensive treatment when CRC is present.

According to American Cancer Society, the US Multi-Society Task Force on CRC and the American College of Radiology guidelines, screening of adenomatous polyps and CRC in average-risk adults should begin at age 50 years with one of the following options: 1) annual guaiac Fecal Occult Blood
Test (gFOBT) or Fecal Immunochemical Test (FIT) or testing stool for exfoliated cell DNA, 2) flexible sigmoidoscopy every 5 years; 3) colonoscopy every 10 years, 4) double-contrast barium enema every 5 years, or 5) CT colonography every 5 years $(7-10)$.

Previously, several published researches from various countries with different races and cultures have reported patient barriers to CRC screening as health illiteracy and lack of knowledge, negative attitudes about prevention and cancer, financial concerns and lack of physician's recommendation for screening tests $(2,11-25)$.

Also, in a study by Beydoun and Beydoun in US, predictors of CRC screening behaviors among average-risk older adults included older age, male gender, marriage, higher education, higher income, white race, non-Hispanic ethnicity, smoking history, presence of chronic diseases, family history of CRC, usual source of care, physician recommendation, utilization of other preventive health services, and health insurance coverage (26). There are a few data about CRC screening knowledge and attitudes of Iranians in literature and most of them include a small sample size $(10,27)$.

Considering the ethnic and cultural dispersion and demographic characteristics of Iran, and lack of a national program for CRC screening, we performed the current study on a large sample of Eastern Iranian population to investigate Persian's awareness and attitudes toward CRC and obstacles to screening. 


\section{Methods}

This is a cross-sectional study on 1060 randomly selected individuals older than 40 years who referred to Razavi Hospital of Mashhad, Iran, between September the $1^{\text {st }}, 2012$ and February the $28^{\text {th }}, 2013$ as patients or their visitors involved in a face to face interview by two trained nurses to fill a designed questionnaire including demographics, knowledge about symptoms, risk factors and screening tests of CRC and reasons for not being screened. Also, those aware of the screening tests were asked about the way of notification.

CRC risk factors in the questionnaire consisted of 8 items: 1) excessive alcohol intake, 2) smoking, 3) obesity, 4) positive history of CRC in the first or second degree relatives, 5) high calorie diet, 6) high red meat consumption, 7) sedentary life style, 8) diets containing high saturated fats (28).

CRC symptoms consisted of 7 items: 1) bloody stool, 2) change in bowel habits, 3) weight loss, 4) generalized weakness, 5) nausea and vomiting, 6) intermittent abdominal pain, 7) abdominal bloating (28).

In our study we evaluated the knowledge about the most available CRC screening tests: 1) fecal occult blood test, 2) flexible sigmoidoscopy, 3) colonoscopy.

Since the purpose of this study was finding the knowledge of people toward CRC screening, patients with past or present history of inflammatory bowel diseases (crohn's disease and ulcerative colitis), CRC or polyps were excluded. After interview, every person received a free pamphlet, provided by Razavi Hospital CRC Research Group about CRC including definition, risk factors, symptoms, importance of screening and standard screening tests.

The study questionnaire followed the constructions of the Health Belief Model as a guide for validity (29). Cronbach's alpha was used to evaluate the reliability which was $99 \%$. Data were analyzed by descriptive and analytical statistics using SPSS 19 (SPSS Inc., Chicago, IL, USA) and a $P$ value of $<0.050$ was considered significant.

To compare the level of knowledge among men and women, employment status, insurance status and people in various levels of education, Chi-square (for qualitative variables) and one way ANOVA (for quantitative variables) tests were used. Scoring of different parts of questionnaire was carried out according to Table 1.

\section{Results}

1060 questionnaires were completed by the respondents 59 of which were excluded due to history of CRC and polyp or inflammatory bowel disease. The sample of 1001 people consisted of 478 males and 523 females with the age range of 40 to 88 years $($ mean $=55, \mathrm{SD}=10.9)$. Socio-demographic characteristics of the study participants are shown in Table 2. At the time of this study, most of the participants were married (98.0\%). The majority of persons had secondary school education or less (78.2\%) and were employed or retired (52.1\%) with monthly income of less than 400 US dollars (90.5\%). Also, $88.3 \%$ of individuals had health insurance. Forty persons $(4.0 \%)$ reported a positive history of CRC in their first or second degree relatives. In our survey, only $4.2 \%$ of respondents reported prior screening for CRC and other 95.8\% had never been tested before.

More than $90 \%$ of the participants in this study did not have any knowledge of CRC risk factors, symptoms or the screening tests. Table 3 shows the knowledge of participants about CRC and screening tests.

Most of the people mentioned "did not have any symptom or

Table 1. Scoring of different parts of questionnaire

\begin{tabular}{ll}
\hline Part & Scoring \\
\hline \multirow{3}{*}{ Awareness of the risk factors of } & Lack of information= nothing \\
CRC & Aware of $1-2$ items= low \\
& Aware of 3-5 items= medium \\
& Aware of 6-8 items= high \\
& Lack of information= nothing \\
Awareness of the symptoms of CRC & Aware of $1-2=$ low \\
& Aware of 3-4 items= medium \\
& Aware of 5-7 items= high \\
& Lack of information= nothing \\
& Aware of 1 item= low \\
Awareness of the screening tests & Aware of 2 items= medium \\
& Aware of 3 items= high \\
\hline
\end{tabular}

Table 2. Demographic characteristics of the study participants $(\mathrm{N}=$ 1001)

\begin{tabular}{|c|c|c|}
\hline Variables & Number & $\%$ \\
\hline \multicolumn{3}{|l|}{ Gender } \\
\hline Male & 478 & 47.8 \\
\hline Female & 523 & 52.2 \\
\hline \multicolumn{3}{|l|}{ Marital Status } \\
\hline Single & 20 & 2.0 \\
\hline Married & 981 & 98.0 \\
\hline Widowed/divorced & 0 & 0.0 \\
\hline \multicolumn{3}{|l|}{ Education } \\
\hline Diploma or less & 783 & 78.2 \\
\hline Some college or Bachelor's degree & 190 & 19.0 \\
\hline Master's degree or more & 28 & 2.8 \\
\hline \multicolumn{3}{|l|}{ Employment status } \\
\hline Employed or Retired & 522 & 52.1 \\
\hline Unemployed & 479 & 47.9 \\
\hline \multicolumn{3}{|l|}{ Monthly income (US dollar) } \\
\hline$<200$ & 215 & 21.5 \\
\hline $200-400$ & 691 & 69.0 \\
\hline$>400$ & 76 & 7.6 \\
\hline Missing & 19 & 1.9 \\
\hline \multicolumn{3}{|l|}{ Family history of CRC } \\
\hline Yes & 40 & 4.0 \\
\hline No & 961 & 96.0 \\
\hline \multicolumn{3}{|l|}{ Health insurance } \\
\hline Yes & 884 & 88.3 \\
\hline No & 117 & 11.7 \\
\hline \multicolumn{3}{|l|}{ Prior history of CRC screening } \\
\hline Yes & 42 & 4.2 \\
\hline No & 959 & 95.8 \\
\hline
\end{tabular}


problem" and "did not think it was needed" as the main reasons for not having CRC screening tests (reported in 40.1\%, 32.5\% respectively). Also $12.7 \%$ of the respondents cited "physician did not recommend the test", as their reason. Findings showed that "fear of the screening test", "fear of advanced CRC" and "the cost of test", were the least cited barriers for participation in CRC screening tests. $0.5 .3 \%$ of the participants who had some knowledge about screening tests of CRC, expressed university education, physician recommendation, family members, magazines and newspapers, as the primary sources of their notification.

Analysis of data proved that there was no relationship between variables such as gender, health insurance status, family history and knowledge of people about CRC risk factors and symptoms (Table 4).

Although having a positive family history of CRC did not increase the clinical knowledge among high-risk group, there was a significant association $(P=0.012)$ between family history and awareness of the screening tests (Table 4 ).

Comparison between knowledge of risk factors and symptoms of CRC and age of participants indicated a significant difference $(P=0.031)$ as the older people had more knowledge. Employment, education and higher incomes had positive influence on the perception of individuals toward CRC risk factors, symptoms and screening tests, too (Table 4).

\section{Discussion}

The findings of this study demonstrated that $95.8 \%$ of our people have never had screening for CRC before and even, more than $90 \%$ did not have any knowledge of CRC risk factors, symptoms or the screening tests. This data is far from the current situation in the US where about $65 \%$ of people aged 50 or older have received CRC screening test consistent

Table 3. Distribution of knowledge score toward risk factors and symptoms of CRC and screening tests

\begin{tabular}{lccc}
\hline & $\begin{array}{c}\text { Knowledge of } \\
\text { symptoms }\end{array}$ & $\begin{array}{c}\text { Knowledge of } \\
\text { risk factors }\end{array}$ & $\begin{array}{c}\text { Knowledge of } \\
\text { screening tests }\end{array}$ \\
\hline High & $0.2 \%$ & $0.1 \%$ & $0.3 \%$ \\
Medium & $0.8 \%$ & $0.7 \%$ & $0.8 \%$ \\
Low & $8.0 \%$ & $7.1 \%$ & $4.2 \%$ \\
Nothing & $91.0 \%$ & $92.1 \%$ & $94.7 \%$ \\
\hline
\end{tabular}

Table 4. Association between knowledge about CRC and the study variables

\begin{tabular}{lccc}
\hline Characteristics & $\begin{array}{c}\text { Knowledge } \\
\text { of risk factors } \\
(\boldsymbol{P} \text { value })\end{array}$ & $\begin{array}{c}\text { Knowledge } \\
\text { of symptoms } \\
(\boldsymbol{P} \text { value })\end{array}$ & $\begin{array}{c}\text { Knowledge of } \\
\text { screening Tests } \\
(\boldsymbol{P} \text { value })\end{array}$ \\
\hline Gender & 0.546 & 0.178 & 0.532 \\
Age & 0.032 & 0.038 & 0.236 \\
Family History & 0.272 & 0.380 & 0.011 \\
Health Insurance & 0.402 & 0.253 & 0.339 \\
Marital Statues & 0.018 & 0.957 & 0.158 \\
Employment & 0.003 & 0.011 & 0.005 \\
Education & 0.001 & 0.001 & 0.001 \\
Income & 0.001 & 0.002 & 0.031 \\
\hline
\end{tabular}

with current guidelines and it is still below target rates (30). Like other studies, age, has been found as an important factor in the knowledge of people with rates higher among older individuals, which can be due to increased risk of comorbidities in older people that force them to seek medical advice more than the others, although this must be evaluated in further studies with emphasizing on relationship between co-morbidities and CRC screening rate $(15,16,31)$.

One of the most important barriers to CRC screening in our population is limited literacy that deprives them of general or particular awareness and information. This is consistent with the results of the other studies $(13,20,23,26,27,32)$.

As mentioned in prior studies $(2,10,13,26,33)$, we also realized that employment and higher income can be promoters to encourage average risk people to undergo screening and on the other hand, low socio-economic condition specially in rural areas can be a barrier in this regard.

Unlike other studies that reported absence of health insurance as a threat, we did not find any correlation between health insurance and participation in screening which can be due to lack of enough coverage for the expensive screening tests by the insurance organizations in Iran $(2,11,15,26,31)$.

Although positive family history of CRC did not increase the knowledge of our population about CRC symptoms and risk factors, it could raise their awareness of screening tests that was consistent with findings in previous studies $(10,15,26)$.

Most of the individuals in our survey perceived themselves to be in good health and did not think the screening tests were needed. This fact accompanying by failure of physician recommendation were the most cited reasons for not having screening tests which shows that perception of CRC risk in general population and healthcare system plays an important role in the tendency of adults toward screening and prevention. This is consistently reported in several other papers too $(10,11,14,16,19,20,23,24,27,31,32,33-35)$.

In a study by Omran and Ismail in Jordan, the most common sources of information about CRC screening were respectively family members, newspapers and magazines, television or radio and physicians (25). In accordance to their findings, in our study those who had some knowledge about screening tests of CRC, expressed university education, physician recommendation, family members, magazines and newspapers, respectively as the primary sources of their notification that explains the remarkable role of educational and healthcare system in the improvement of public knowledge and perception toward CRC screening.

In this study we proposed gFOBT instead of FIT as a tool for CRC screening, because it's cheaper and more available in primary laboratories in Iran, particularly in small cities. Although FIT, with fewer tests, is more sensitive and needs no dietary restriction (36).

In our study we had limitation in evaluating the influence of our CRC pamphlet (cited in methodology section) on improvement of people's awareness, therefore further studies must be planned to investigate the effect of such educational programs on medical knowledge of people to persuade them to undergo screening tests. Also the second barrier to this research was finding the exact number of patients in our sample that referred to Razavi hospital and separating the results to two groups (patients and general population) to 
remove the probable bias of selection.

\section{Conclusion}

Lack of knowledge in people, particularly those in lower socioeconomical class with limited literacy is the most important barrier to CRC screening. So, designing educational programs involving physicians and media is important to improve CRC screening rates. In a developing country like Iran with an acceptable infrastructure of healthcare system, training family physicians on CRC screening based on national or international guidelines to perform office-based fecal occult blood test and refer patients with a positive test for a diagnostic colonoscopy can be a useful strategy.

\section{Acknowledgments}

We thank the Research and Education Department of Razavi Hospital for funding and support of this study. We also thank Dr Ramin Sadeghi for revising the manuscript. Authors acknowledge the CRC Research Group of Razavi Hospital who provided help during the research.

Ethical issues

All the patients were fully informed and ethical consent was obtained.

\section{Competing interests}

The authors declare that they have no competing interests.

\section{Authors' contributions}

FB and KG were the main investigators, participated in the design and conducting the study, drafted and edited the manuscript. Al participated in the design of the study and conducted the statistical analysis. SA, NJ, FK, AA, MV and TT participated in the design and conducted the data gathering for the study. HA participated in the design of the study and edited the manuscript for final submission. All authors read and approved the final manuscript. FB is the study guarantors.

Authors' affiliations

Research and Education Department, Razavi Hospital, Mashhad, Iran.

\section{References}

1. Jemal A, Bray F, Center MM, Ferlay J, Ward E, Forman D. Global cancer statistics. CA Cancer J Clin 2011; 61: 69-90. doi: 10.3322/caac.20107

2. Sung JJ, Choi SY, Chan FK, Ching JY, Lau JT, Griffiths S. Obstacles to colorectal cancer screening in Chinese: a study based on the health belief model. Am J Gastroenterol 2008; 103: 974-81. doi: 10.1111/j.1572-0241.2007.01649.x

3. Tu SP, Taylor V, Yasui Y, Chun A, Yip MP, Acorda E, et al. Promoting culturally appropriate colorectal cancer screening through a health educator. Cancer 2006; 107: 959-66. doi: 10.1002/cncr.22091

4. Pourhoseingholi MA, Zali MR. Colorectal cancer screening: Time for action in Iran. World J Gastrointest Oncol 2012; 4: 82-3. doi: 10.4251/wjgo.v4.i4.82

5. Consolo P, Luigiano C, Strangio G, Scaffidi MG, Giacobbe G, Di Giuseppe G, et al. Efficacy, risk factors and complications of endoscopic polypectomy: ten year experience at a single center. World journal of gastroenterology: WJG 2008; 14: 2364. doi: 10.3748/wjg.14.2364

6. Zauber AG, Winawer SJ, O'Brien MJ, Lansdorp-Vogelaar I, van Ballegooijen M, Hankey BF, et al. Colonoscopic polypectomy and long-term prevention of colorectal-cancer deaths. N Engl J Med 2012; 366: 687-96. doi: 10.1056/NEJMoa1100370

7. Smith RA, Cokkinides V, Brawley OW. Cancer Screening in the United States, 2012 A Review of Current American Cancer Society Guidelines and Current Issues in Cancer Screening. CA Cancer J Clin 2012; 62: 129-42. doi: 10.3322/caac.20143

8. Levin B, Lieberman DA, McFarland B, Smith RA, Brooks D, Andrews KS, et al. Screening and Surveillance for the Early Detection of Colorectal Cancer and Adenomatous Polyps, 2008: A Joint Guideline from the American Cancer Society, the US Multi-Society Task Force on Colorectal Cancer, and the American College of Radiology. CA Cancer J Clin 2008; 58: 130-60. doi: 10.3322/ca.2007.0018

9. Winawer S, Fletcher R, Rex D, Bond J, Burt R, Ferrucci J, et al. Colorectal cancer screening and surveillance: clinical guidelines and rationale - update based on new evidence. Gastroenterology 2003; 124: 544-60. doi: 10.1053/gast.2003.50044

10. Salimzadeh $H$, Delavari A, Montazeri A, Mirzazadeh A. Knowledge and practice of iranians toward colorectal cancer, and barriers to screening. Int J Prev Med 2012; 3: 29-35.

11. O'Malley A, Beaton E, Yabroff K, Abramson R, Mandelblatt J. Patient and provider barriers to colorectal cancer screening in the primary care safety-net. Prev Med 2004; 39: 56. doi: 10.1016/j. ypmed.2004.02.022

12. James AS, Campbell MK, Hudson MA. Perceived barriers and benefits to colon cancer screening among African Americans in North Carolina: how does perception relate to screening behavior? Cancer Epidemiol Biomarkers Prev 2002; 11: 529-34.

13. Green PM, Kelly BA. Colorectal cancer knowledge, perceptions, and behaviors in African Americans. Cancer Nurs 2004; $27: 206$ 15. doi: 10.1097/00002820-200405000-00004

14. Jones RM, Woolf SH, Cunningham TD, Johnson RE, Krist AH, Rothemich SF, et al. The relative importance of patient-reported barriers to colorectal cancer screening. Am J Prev Med 2010; 38: 499-507.

15. Tessaro I, Mangone C, Parkar I, Pawar V. Peer reviewed: knowledge, barriers, and predictors of colorectal cancer screening in an appalachian church population. Prev Chronic Dis 2006; 3: A123.

16. Berkowitz Z, Hawkins NA, Peipins LA, White MC, Nadel MR. Beliefs, risk perceptions, and gaps in knowledge as barriers to colorectal cancer screening in older adults. J Am Geriatr Soc 2008; 56: 307-14. doi: 10.1111/j.1532-5415.2007.01547.x

17. Holmes-Rovner M, Williams GA, Hoppough S, Quillan L, Butler R, Given CW. Colorectal cancer screening barriers in persons with low income. Cancer Pract 2002; 10: 240-7. doi: 10.1046/j.15235394.2002.105003.x

18. Tang TS, Solomon LJ, McCracken LM. Barriers to Fecal Occult Blood Testing and Sigmoidoscopy Among Older ChineseAmerican Women. Cancer Pract 2001; 9: 277-82. doi: 10.1046/j.1523-5394.2001.96008.x

19. Klabunde CN, Schenck AP, Davis WW. Barriers to colorectal cancer screening among Medicare consumers. Am J Prev Med 2006; 30: 313. doi: 10.1016/j.amepre.2005.11.006

20. Wee CC, McCarthy EP, Phillips RS. Factors associated with colon cancer screening: the role of patient factors and physician counseling. Prev Med 2005; 41: 23. doi:10.1016/j. ypmed.2004.11.004

21. Greiner KA, Born W, Nollen N, Ahluwalia JS. Knowledge and perceptions of colorectal cancer screening among urban African Americans. J Gen Intern Med 2005; 20: 977-83. doi: 10.1007/ s11606-005-0244-8

22. Goodman MJ, Ogdie A, Kanamori MJ, Canar J, O'Malley AS. Barriers and facilitators of colorectal cancer screening among mid-Atlantic Latinos: Focus group findings. Ethn Dis 2006; 16: 255-61.

23. McCaffery K, Wardle J, Waller J. Knowledge, attitudes, and behavioral intentions in relation to the early detection of colorectal 
cancer in the United Kingdom. Prev Med 2003; 36: 525-35. doi: 10.1016/s0091-7435(03)00016-1

24. Koo JH, Arasaratnam MM, Liu K, Redmond DM, Connor SJ, Sung JJY, et al. Knowledge, perception and practices of colorectal cancer screening in an ethnically diverse population. Cancer Epidemiol 2010; 34: 604-10. doi: 10.1016/j.canep.2010.05.013

25. Omran S, Ismail AA. Knowledge and beliefs of Jordanians toward colorectal cancer screening. Cancer Nurs 2010; 33: 141. doi: $10.1097 /$ ncc.0b013e3181b823f3

26. Beydoun HA, Beydoun MA. Predictors of colorectal cancer screening behaviors among average-risk older adults in the United States. Cancer Causes Control 2008; 19: 339-59. doi: 10.1007/s10552-007-9100-y

27. Roozitalab M, Moatari M, Gholamzadeh S, SaberiFiroozi M, Zare N. [The effect of health belief on participation of the official administrative personnel in colorectal cancer screening programs in Shiraz University of Medical Sciences: 2004]. Govaresh 2012; 13: 19-24.

28. Libbuti SK, Saltz LB, Willett CG. Cancer of the colon. In: DeVita VT, TS Lawrence, SA Rosenberg, editors. Cancer Principles and Practice of Oncology. 9th ed. Philadelphia: Wolters Kluwer/ Lippincott Williams \& Wilkins; 2011. p. 1084-90.

29. Janz N, Champion V, Strecher V, Glanz K, Rimer B, Lewis F. The health belief model. In: Glanz k, Rimer BK, Lewis FM, editors. Health behavior and health education: Theory, research and practice. San Francisco: Jones and Bartlett; 2002. p. 45-66. doi: 10.1177/109019819101800409

30. CDC Vital Signs [internet]. Atlanta GA: Centers for Disease
Control and Prevention; 2014 [updated 2013 May 11; cited 2014 April 19]. Available from: http://www.cdc.gov/vitalsigns

31. Guessous I, Dash C, Lapin P, Doroshenk M, Smith RA, Klabunde CN. Colorectal cancer screening barriers and facilitators in older persons. Prev Med 2010; 50: 3. doi: 10.1016/j. ypmed.2009.12.005

32. Miller D, Brownlee C, McCoy T, Pignone M. The effect of health literacy on knowledge and receipt of colorectal cancer screening: a survey study. BMC Fam Pract 2007; 8: 16.doi: 10.1186/14712296-8-16

33. Koo JH, Leong RWL, Ching J, Yeoh KG, Wu DC, Murdani A, et al. Knowledge of, attitudes toward, and barriers to participation of colorectal cancer screening tests in the Asia-Pacific region: a multicenter study. Gastrointest Endosc 2012; 76: 126-35. doi: 10.1016/j.gie.2012.03.168

34. Janz NK, Wren PA, Schottenfeld D, Guire KE. Colorectal cancer screening attitudes and behavior: a population-based study. Prev Med 2003; 37: 627-34. doi: 10.1016/j.ypmed.2003.09.016

35. Gennarelli M, Jandorf L, Cromwell C, Valdimarsdottir H, Redd W, Itzkowitz S. Barriers to colorectal cancer screening: inadequate knowledge by physicians. Mt Sinai J Med 2005; 72: 36. doi: 10.1016/s0016-5085(01)83002-x

36. Smith A, Young GP, Cole SR, Bampton P. Comparison of a brush-sampling fecal immunochemical test for hemoglobin with a sensitive guaiac-based fecal occult blood test in detection of colorectal neoplasia. Cancer 2006; 107: 2152-9.doi: 10.1002/ cncr. 22230

\section{Key Messages}

Implications for policy makers

- There are so many barriers like education, employment and income to Colorectal Cancer (CRC) screening in a developing country like Iran.

- There is not enough coverage for the expensive screening tests by the insurance organizations in Iran.

- The role of health system infrastructure in screening programs' participation is essential.

- Designing educational programs involving physicians and media is important to improve CRC screening rates.

\section{Implications for public}

In Iran, Colorectal Cancer (CRC) is the third most common cancer in women and fifth in men and is known as the fifth cause of cancer death. CRC is mostly prevalent in older people but in Iran there has been a great rise in its incidence among young individuals in recent decades, especially in those with positive history of CRC in the first or second degree relatives. The majority of CRC incidences and deaths can be prevented by applying public awareness about cancer prevention and by raising the use of available screening tests. By screening, we are able to find and remove adenomatous polyps which are in premalignant state of CRC. Also regular screening at recommended intervals improves the probability of cure with less extensive treatment when CRC is present. 